\title{
PENGARUH KETERIKATAN KERJA, IKLIM ORGANISASI DAN KEPUASAN KERJA TERHADAP KINERJA KARYAWAN PT XYZ
}

\author{
Michelle \\ Program Studi Magister Manajemen Universitas Tarumanagara \\ michelle.sofjan@gmail.com \\ Rostiana \\ Program Studi Magister Manajemen Universitas Tarumanagara
}

Masuk : 06-12-2019, revisi : 20-12-2019 diterima untuk diterbitkan : 21-12-2019

\begin{abstract}
This study aims to explain the role of work engagement, organizational climate, and job satisfaction on employee performance at PT XYZ. This research is a causality research conducted by cross sectional method. The sampling technique is done by convenience sampling. Data collection was carried out using a questionnaire instrument which was then analyzed using multiple linear regression analysis. The results of the study explained that work engagement, job satisfaction, and organizational climate play a positive role on the performance of employees at PT XYZ. These results explain that more employees feel they have a good attachment to the company, have satisfaction with the work done, and feel a conducive organizational climate that can support employees at PT XYZ to show better performance.
\end{abstract}

Keywords : performance, work engagement, job satisfaction, and organizational climate.

Abstrak : Penelitian ini bertujuan untuk menjelaskan mengenai peran keterikatan kerja, iklim organisasi, dan kepuasan kerja terhadap kinerja karyawan di PT XYZ. Penelitian ini merupakan penelitian kausalitas yang dilakukan dengan metode cross sectional. Teknik pengambilan sampel dilakukan dengan convenience sampling. Pengumpulan data dilakukan dengan menggunakan instrumen kuesioner yang kemudian dianalisis dengan menggunakan analisis regresi linier berganda. Hasil penelitian menjelaskan bahwa keterikatan kerja, kepuasan kerja, dan iklim organisasi berperan positif terhadap kinerja karyawan di PT XYZ. Hasil ini menerangkan bahwa semakin karyawan merasa memiliki keterikatan yang baik dengan perusahaan, memiliki kepuasan terhadap pekerjaan yang dilakukan, dan merasakan iklim organisasi yang kondusif dapat mendukung karyawan di PT XYZ untuk menunjukkan kinerja yang lebih baik.

Kata kunci : kinerja, keterikatan kerja, kepuasan kerja, dan iklim organisasi.

\section{PENDAHULUAN}

Saat ini, perkembangan ekonomi dunia semakin kompetitif termasuk perkembangan perekonomian di Indonesia. Hal ini menyebabkan perubahan regulasi yang membuat perusahaan dapat ikut serta dalam penyejahteraan masyarakat baik dalam lingkungan internal maupun eksternal perusahaan. Banyak sekali perusahaan yang berusaha untuk dapat bersaing dengan para kompetitor di dalam industri bisnis yang dijalankannya. Salah satu faktor yang berperan penting dalam mendukung perusahaan untuk dapat bersaing dengan para competitor adalah sumber daya manusia. Sumber daya manusia merupakan aset paling berharga dan penting yang dimililki oleh organisasi atau perusahaan, karena tercapainya tujuan suatu organnisasi sangat dipengaruhi oleh faktor manusia (Khandekar \& Sharma, 2006). Manusia berperan sebagai perencana, pelaksana, dan sekaligus pengendali terwujudnya tujuan organisasi atau perusahaan, selain itu tidak ada satupun organisasi yang tidak mempunyai sumber daya manusia sebagai penggerak organisasi atau perusahaan (Ardana et al., 2012). 
PT. XYZ merupakan perusahaan manufaktur Spring Bed di Indonesia. PT. XYZ memproduksi 3 merk spring bed yang telah mempunyai nama di pasar pangsanya. PT. XYZ mempekerjakan kurang lebih 1500 karyawan yang terbagi menjadi 3 wilayah, yaitu Barat, Tengah, dan Timur, yang mempunyai kantor pusat di Jakarta. Namun dengan jumlah karyawan yang besar tersebut, justru menunjukkan kinerja karyawan mengalami penurunan dalam tiga tahun terakhir yang ditunjukkan melalui nilai KPI pada Tabel 1 berikut.

Tabel 1

Rata-rata pencapaian KPI PT. XYZ Tahun 2016 hingga 2018
\begin{tabular}{|c|c|}
\hline Tahun & Rata-rata KPI \\
\hline 2016 & 3,87 \\
\hline 2017 & 3,70 \\
\hline 2018 & 3,47 \\
\hline
\end{tabular}

Sumber: data primer perusahaan.

Penurunan KPI ini juga berdampak pada profit atau keuntungan perusahaan pada tahun 2018, yaitu sebesar 4,5\% sedangkan dari tahun 2017 profit yang didapatkan sebesar 6,5\%. PT. XYZ melihat bahwa faktor kinerja merupakan hal yang sangat penting untuk mencapai tujuan dari perusahaan.

Peneliti telah melakukan wawancara kepada 20 orang karyawan PT. XYZ wilayah Barat yang berkantor di Jakarta yang sudah menjadi karyawan tetap dan lebih dari 1 tahun. 17 dari 20 orang yang peneliti temui menyatakan bahwa mereka tidak mempunyai rasa kepuasan terhadap pekerjaan yang mereka lakukan. Banyak keluhan yang disampaikan terkait ketidakpuasan karyawan, seperti masalah uang lembur yang tidak dibauarkan, pemotongan gaji jika terlambat, tidak ada kenaikan gaji, BPJS yang tidak ditanggung, serta masalah lain yang menimbulkan ketidakpuasan karyawan.

Berbagai kajian akademis terkait faktor-faktor yang dapat mempengaruhi secara langsung atau tidak langsung terhadap kinerja karyawan telah banyak dipublikasikan. Walaupun hasilnya beragam, namun ada benang merah dimana kinerja karyawan di sebuah perusahaan umumnya dipengaruhi oleh banyak faktor, antara lain keterikatan kerja (work engagement), iklim organisasi, dan kepuasan kerja. Adapun tujuan dari penelitian ini, yaitu:

1. Untuk mengetahui peran antara keterikatan kerja (work engagement) pada kinerja karyawan.

2. Untuk mengetahui peran antara iklim organisasi pada kinerja karyawan.

3. Untuk mengetahui peran antara kepuasan kerja pada kinerja karyawan.

4. Untuk mengetahui peran antara keterikatan kerja (work engagement), iklim organisasi, dan kepuasan kerja pada kinerja karyawan.

\section{TINJAUAN LITERATUR}

Kinerja

Koopmans et al. (2014) mendefinisikan kinerja adalah perilaku atau tindakan yang relevan dengan tujuan dari suatu organisasi. Menurut Koopmans et al, terdapat 3 faktor yang menjadi tolok ukur dari kinerja, yaitu : a) Kinerja tugas (Task Performance); b) Kinerja kontekstual (Contextual Performance); c) Perilaku kerja kontraproduktif (Counterproductive Work Behavior)

\section{Keterikatan Kerja (Work Engagement)}

Keterikatan kerja (work engagement) secara umum diartikan sebagai tingkat komitmen dan keterikatan seorang karyawan terhadap organisasinya. Menurut Schaufeli, et al (2012), work engagement diartikan sebagai perilaku kerja yang positif, dapat menyelesaikan pekerjaan dengan daya pikirnya yang digambarkan oleh vigor, dedication, dan absorption. 


\section{Iklim Organisasi}

Litwin dan Stringer (dalam Wirawan, 2007) mengemukakaan iklim organisasi merupakan kualitas lingkungan internal organisasi yang secara relatif terus berlangsung, yang dialami oleh anggota organisasi, mempengaruhi perilaku mereka dan dapat disatukan menjadi satu set karakteristik atau sifat organisasi. Iklim organisasi, dapat diukur melalui lima dimensi, yaitu: a) Responsibility (tanggung jawab); b) Identity (identitas); c) Warmth (kehangatan); d) Support (dukungan); e) Conflict (konflik)

\section{Kepuasan Kerja}

Koesmono (2005) mengemukakan bahwa kepuasan kerja merupakan penilaian, perasaan atau sikap seseorang atau karyawan terhadap pekerjaannya dan berhubungan dengan lingkungan kerja, jenis pekerjaan, kompensasi, hubungan antar teman kerja, hubungan sosial di tempat kerja dan sebagainya. Smith, et al. (2000) secara lebih rinci mengemukakan berbagai dimensi dalam kepuasan kerja yang kemudian dikembangkan menjadi instrumen pengukur variabel kepuasan terhadap beberapa faktor, yakni: 1) Menarik atau tidaknya jenis pekerjaan yang dilakukan oleh pekerja, 2) Jumlah kompensasi yang diterima pekerja, 3) Kesempatan untuk promosi jabatan, 4) Kemampuan atasan dalam memberikan bantuan teknis dan dukungan perilaku, dan dukungan rekan sekerja.

\section{METODOLOGI PENELITIAN}

Penelitian yang dilakukan merupakan penelitian kausalitas dengan metode cross sectional. Penelitian ini sendiri dilakukan dalam kurun waktu 7 bulan, yaitu dari bulan April 2019 hingga November 2019. Populasi yang diteliti dalam penelitian ini adalah seluruh karyawan tetap yang bekerja di PT. XYZ di Jakarta. Teknik pengambilan sampel dilakukan secara convenience sampling, yang mempunyai syarat, sebagai berikut: (a) Sudah bekerja lebih dari 1 tahun; (b) Sudah berstatus karyawan tetap; (c) pendidikan minimal SMA.

Proses pengumpulan data yang dilakukan adalah dengan mendistribusikan kuesioner kepada setiap responden yang menjadi sampel penelitian. Pengukuran jawaban dari setiap responden dijelaskan dengan skala interval yang mengacu pada skala likert. Kemudian data yang telah terkumpul dianalisis secara statistik menggunakan analisis regresi linier berganda. Model peramalan regresi yang baik harus minim dari kesalalahan peramalan. Maka dari itu untuk meminimkan kesalahan dalam peramalan sebelum melakukan regresi harus dilakukan beberapa uji asumsi klasik yaitu uji normalitas, autokorelasi, homokedastisitas dan multikolineritas.

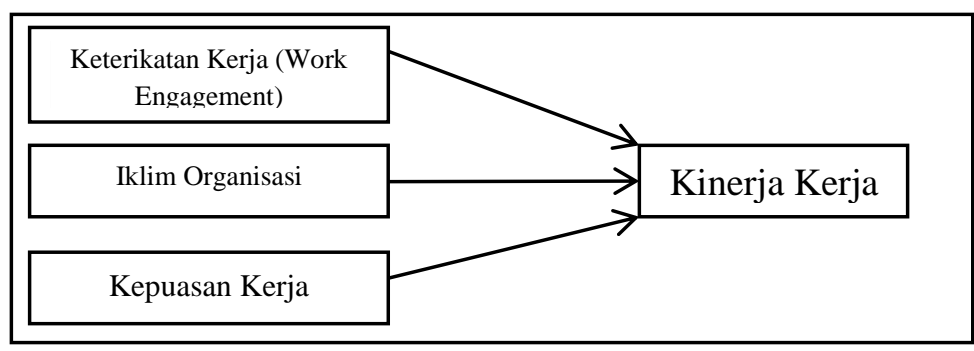

\section{Gambar 1 \\ Model Penelitian}

\section{HASIL DAN PEMBAHASAN}

Tabel 2

Karakteristik Responden

\begin{tabular}{lll} 
Karakteristik & Klasifikasi & Persentase (\%) \\
\hline Usia & 21 - 30 Tahun & 51.6 \\
& 31 - 40 Tahun & 28.1 \\
& 41 - 50 Tahun & 17.6 \\
\multirow{2}{*}{ Jenis Kelamin } & 250 Tahun & 2.6 \\
& Laki-laki & 47.1 \\
& Perempuan & 52.9
\end{tabular}




\begin{tabular}{|c|c|c|c|c|}
\hline Pendidikan & \multicolumn{2}{|l|}{ SMA } & \multicolumn{2}{|c|}{9.2} \\
\hline & \multicolumn{2}{|l|}{ Diploma 3} & \multicolumn{2}{|c|}{11.1} \\
\hline & \multicolumn{2}{|l|}{ Strata 1} & \multicolumn{2}{|c|}{63.4} \\
\hline & \multicolumn{2}{|l|}{ Strata 2} & \multicolumn{2}{|c|}{16.3} \\
\hline \multirow{12}{*}{ Divisi } & \multicolumn{2}{|c|}{ Finance/Accounting/Tax } & \multicolumn{2}{|c|}{24.8} \\
\hline & \multicolumn{2}{|c|}{ Produksi } & \multicolumn{2}{|c|}{3.3} \\
\hline & Admin & & & \\
\hline & HR/GA & & & \\
\hline & Sales & & 1 & \\
\hline & Purchasing & & & \\
\hline & Customer Se & & & \\
\hline & IT & & & \\
\hline & Research \& I & oment & & \\
\hline & Designer & & 2 & \\
\hline & Auditor & & & \\
\hline & Strategic Plar & & & \\
\hline Lama Kerja & 1 - 5 Tahun & & & \\
\hline & 6 - 10 Tahun & & & \\
\hline & $11-15$ Tahu & & & \\
\hline & $>15$ Tahun & & & \\
\hline Nilai Kinerja & Perlu pengen & & 1 & \\
\hline & Memuaskan & & & \\
\hline & Sangat Memı & & & \\
\hline & Istimewa & & & \\
\hline & & el 3 & & \\
\hline & Hasi & Validitas & & \\
\hline No. & Variabel & Indikator & R Hitung & Validitas \\
\hline & & WE1 & 0.794 & valid \\
\hline & & WE2 & 0.833 & valid \\
\hline & & WE3 & 0.856 & valid \\
\hline & & WE4 & 0.819 & valid \\
\hline 1 & Keterikatan Kerja & WE5 & 0.733 & valid \\
\hline & & WE6 & 0.798 & valid \\
\hline & & WE7 & 0.813 & valid \\
\hline & & WE8 & 0.729 & valid \\
\hline & & WE9 & 0.752 & valid \\
\hline & & IK1 & 0.789 & valid \\
\hline & & IK2 & 0.749 & valid \\
\hline & & IK3 & 0.745 & valid \\
\hline 2 & Iklim Organisasi & IK4 & 0.828 & valid \\
\hline & & IK5 & 0.8 & valid \\
\hline & & IK6 & 0.854 & valid \\
\hline & & IK7 & 0.81 & valid \\
\hline & & KEP1 & 0.679 & valid \\
\hline & & KEP2 & 0.75 & valid \\
\hline & & KEP3 & 0.843 & valid \\
\hline & & KEP4 & 0.831 & valid \\
\hline 3 & Kepuasan Kerja & KEP5 & 0.856 & valid \\
\hline & & KEP6 & 0.83 & valid \\
\hline & & KEP7 & 0.865 & valid \\
\hline & & KEP8 & 0.833 & valid \\
\hline & & KEP9 & 0.835 & valid \\
\hline & & KIN1 & 0.682 & valid \\
\hline & & KIN2 & 0.734 & valid \\
\hline & & KIN3 & 0.692 & valid \\
\hline & & KIN4 & 0.78 & valid \\
\hline & & KIN5 & 0.714 & valid \\
\hline & & KIN6 & 0.724 & valid \\
\hline & & KIN7 & 0.734 & valid \\
\hline 4 & Kinerja & KIN8 & 0.683 & valid \\
\hline & & KIN9 & 0.737 & valid \\
\hline & & KIN10 & 0.746 & valid \\
\hline & & KIN11 & 0.735 & valid \\
\hline & & KIN12 & 0.329 & valid \\
\hline & & KIN13 & 0.356 & valid \\
\hline & & KIN14 & 0.19 & valid \\
\hline & & KIN15 & 0.245 & valid \\
\hline
\end{tabular}




$\begin{array}{lll}\text { KIN16 } & 0.389 & \text { valid } \\ \text { KIN17 } & 0.18 & \text { valid } \\ \text { KIN18 } & 0.164 & \text { valid }\end{array}$

Tabel 3 menunjukkan dimana masing-masing indicator variabel dalam penelitian ini memiliki nilai lebih besar dari $r$ table yaitu 0.159 . Maka menunjukkan bahwa setiap item valid dalam mengukur dan dapat mengambarkan data variabel yang diteliti.

\section{Tabel 4}

\begin{tabular}{llll}
\multicolumn{4}{c}{ Hasil Uji Reliabilitas } \\
No. & Variabel & Cronbach Alpha & Keterangan \\
\hline 1 & Keterikatan Kerja & 0.922 & Reliabel \\
2 & Iklim Organisasi & 0.903 & Reliabel \\
3 & Kepuasan Kerja & 0.933 & Reliabel \\
4 & Kinerja & 0.825 & Reliabel \\
\hline
\end{tabular}

Tabel 4 menunjukkan nilai Cronbach alpha masing-masing variabel memiliki nilai > 0,50; yang berarti instrument penlitian ini layak digunakan.

\section{Tabel 5}

Hasil Uji Regresi Linier Berganda

\begin{tabular}{llllll}
\hline \multirow{2}{*}{ Model } & \multicolumn{2}{l}{ Unstandardized Coefficients } & $\begin{array}{l}\text { Standardized } \\
\text { Coefficients } \\
\text { Beta }\end{array}$ & $\mathrm{t}$ & Sig. \\
& $\mathrm{B}$ & Std. Error & Betal & \\
\hline (Constant) & 4.445 & 0.357 & & 12.441 & 0 \\
Keterikatan Kerja & 0.042 & 0.009 & 0.359 & 4.513 & 0 \\
Kepuasan Kerja & 0.03 & 0.008 & 0.245 & 3.601 & 0 \\
Iklim Organisasi & 0.047 & 0.016 & 0.233 & 2.881 & 0.005 \\
R Square & 0.485 & & & & \\
F Statistik & 46.855 & & & & \\
Signifikansi & 0.0000 & & & & \\
\hline
\end{tabular}

Tabel 5 menunjukkan hasil uji regresi linier berganda, nilai R square sebesar 0,485 atau 48,5 $\%$ yang artinya keterikatan kerja, iklim organisasi, dan kepuasan kerja berperngaruh sebanyak 48,5\% terhadap kinerja karyawan, 51,5\% adalah variabel yag diluar dari penelitian ini. Dari table ini juga bisa didapatkan persamaan regresi, yaitu:

$$
\mathrm{KIN}=4,445+0,042 \mathrm{WE}+0,047 \mathrm{IK}+0,030 \mathrm{KEP}
$$

Dari tabel di atas, diperoleh nilai signifikan hasil uji $\mathrm{F}$ sebesar 0,000. Oleh karena nilai signifikan hasil uji simultan < 0,05 maka Ho ditolak dan disimpulkan bahwa keterikatan kerja, iklim kerja dan kepuasan kerja secara bersama-sama berpengaruh terhadap kinerja kayawan.

\section{Hasil Uji Asumsi Klasik}

Tabel 6

Hasil uji normalitas

\begin{tabular}{ll}
\hline & $\begin{array}{l}\text { Unstandardized } \\
\text { Residual }\end{array}$ \\
\hline Kolmogorov-Smirnov Z & 0.546 \\
Asymp. Sig. (2-tailed) & 0.927 \\
\hline
\end{tabular}

Hasil uji normalitas pada tabel 6 menunjukkan nilai signifikan hasil uji normalitas Kolmogorv Smirnov sebesar 0,546. Oleh karena nilai signifikan hasil uji normalitas > 0,05 maka dapat disimpulkan bahwa sebaran data residual regresi telah berdistribusi normal, dengan demikian syarat normalitas terpenuhi.

Tabel 7

Hasil Uji Heterokedastisitas

\begin{tabular}{llll} 
Model & & $\mathrm{t}$ & Sig. \\
\hline 1 & (Constant) & 5.078 & .000 \\
& WE & -.523 & .602 \\
& KEP & .099 & .921 \\
& IK & -1.357 & .177 \\
\hline
\end{tabular}


Tabel 7 di atas menunjukakn bahwa seluruh variabel bebas memiliki nilai signifikansi > 0,05 yang berarti tidak terjadi heteroskedastisitas dalam model regresi

\section{Tabel 8}

\section{Hasil Uji Multikolinearitas}

\begin{tabular}{|c|c|c|c|}
\hline \multicolumn{4}{|c|}{ Coefficients $^{a}$} \\
\hline & & \multicolumn{2}{|c|}{ Collinearity Statistics } \\
\hline \multicolumn{2}{|l|}{ Model } & Tolerance & VIF \\
\hline \multirow[t]{3}{*}{1} & WE & .545 & 1.835 \\
\hline & KEP & .745 & 1.343 \\
\hline & IK & .530 & 1.887 \\
\hline
\end{tabular}

Tabel 8 di atas menunjukkan hasil uji multikolinearitas bahwa nilai VIF seluruh variabel bebas < 10 dan nilai tolerance seluruh varabel bebas telah melebihi 0,1 , maka dapat disimpulkan data bebas dari gejala multikolinieritas.

\section{Pengujian Hipotesis}

\section{1) Hipotesis 1}

Nilai signifikan pengaruh variabel keterikatan kerja (WE) terhadap kinerja karyawan (KIN) adalah sebesar 0,000 dengan koefisien regresi bertanda positif. Oleh karena nilai signifikan yang diperoleh $<0,05$ dan koefisien regresi bertanda positif maka Ho ditolak dan disimpulkan bahwa keterikatan kerja berpengaruh positif dan signifikan terhadap kinerja karyawan. Hal ini menunjukkan bahwa semakin tinggi keterikatan kerja karyawan terhadap perusahaan maka semakin tinggi kinerjanya, begitu sebaliknya. Hal ini mendukung hipotesis 1 dalam penelitian ini sehingga hipotesis 1 diterima.

\section{2) Hipotesis 2}

Hasil pengujian hipotesis menunjukkan bahwa dengan nilai koefisien regresi sebesar 0,005 maka iklim organisasi berpengaruh positif terhadap kinerja. Nilai signifikansi sebesar $0,005<0,05$ maka iklim organisasi berpengaruh signifikan terhadap kinerja pegawai. Artinya iklim organisasi di PT. XYZ mempunyai pengaruh pada peningkatan kinerja pegawainya. Sehingga dengan iklim organisasi yang baik akan mendorong tingginya kinerja karyawan.

\section{3) Hipotesis 3}

Hasil pengujian hipotesis menunjukkan bahwa dengan nilai koefisien regresi sebesar 0,000 maka kepuasan kerja berpengaruh positif terhadap kinerja. Nilai signifikansi sebesar $0,000<0,05$ maka kepuasan kerja berpengaruh signifikan terhadap kinerja pegawai. Artinya kepuasan kerja di PT. XYZ mempunyai pengaruh pada peningkatan kinerja pegawainya. Hal ini menunjukkan bahwa semakin tinggi kepuasan kerja karyawan terhadap perusahaan maka semakin tinggi kinerjanya.

\section{KESIMPULAN}

\section{1) Pengaruh kepuasan kerja terhadap kinerja karyawan}

Keterikatan kerja (work engagement) berpengaruh positif dan signifikan terhadap kinerja karyawan, semakin tinggi work engagement karyawan maka semakin tinggi kinerja karyawan, begitu sebaliknya. Hal ini dibuktikan dengan nilai signifikan pengaruh variabel keterikatan kerja (WE) terhadap kinerja karyawan (KIN) adalah sebesar 0,000 dengan koefisien regresi bertanda positif. Oleh karena nilai signifikan yang diperoleh $<0,05$ dan koefisien regresi bertanda positif maka Ho ditolak dan disimpulkan bahwa keterikatan kerja berpengaruh positif dan signifikan terhadap kinerja karyawan. Hal ini menunjukkan bahwa semakin tinggi keterikatan kerja karyawan terhadap perusahaan maka semakin tinggi kinerjanya, begitu sebaliknya. Hal ini mendukung hipotesis 1 dalam penelitian ini sehingga hipotesis 1 diterima. Hal penting yang ditemukan dalam penelitian ini adalah bahwa dalam konteks keterikatan kerja, karyawan di PT XYZ memiliki komitmen yang kuat untuk perusahaan. Mereka bangga 
pada pekerjaannya, antusias dan selalu penuh semangat dalam bekerja. Hal ini harus dipertahankan menjadi salah satu keunggulan perusahaan. Pihak manajemen PT XYZ harus mampu menjaga rasa bangga karyawannya dengan menciptakan suasana kondusif yang dapat mempertahankan keterikatan tersebut.

2) Pengaruh iklim organisasi terhadap kinerja karyawan

Iklim organisasi berpengaruh dan signifikan terhadap kinerja karyawan. Nilai Variabel Iklim Organisasi (IK) tidak berpengaruh terhadap kinerja karyawan (KIN), dikarenakan nilai signifikansinya sebesar 0,005 . Hal ini mendukung hipotesis 2 di dalam penelitian ini. Hal ini menunjukkan bahwa iklim organisasi yang baik tentu akan mendorong tingginya kinerja karyawan. Mengacu pada hasil analisis data survei dan hasil penelitian terkait iklim organisasi, maka PT. XYZ perlu mengembangkan lagi pola komunikasi terbuka dengan karyawan agar terbentuk keterbukaan. Perlu diingat bahwa iklim organissai tidak terbentuk begitu saja, perlu waktu lama, komitmen, dan konsistensi dalam penerapan nilai-nilai dan budaya organisasi. Karena itu harus menjadi rencana strategis perusahaan yang terintegrasi dengan visi misi jangka panjang.

\section{3) Pengaruh kepuasan kerja terhadap kinerja karyawan}

Variabel kepuasan kerja (KEP) berpengaruh terhadap kinerja karyawan (KIN), hal ini dikarenakan nilai signifikansinya sebesar 0,000. Hal ini mendukung hipotesis 3 di dalam penelitian ini. Hal ini menunjukkan bahwa kepuasan kerja yang baik akan membantu mendorong tingginya kinerja karyawan. Dengan demikian kepuasan kerja berpengaruh positif dan signifikan terhadap kinerja karyawan. Analisis data menunjukkan ada beberapa poin-poin yang harus diperhatikan olehb PT.XYZ mengenai kepuasan karyawan, khususnya tentang gaji. Namun ada juga yang dinilai memuaskan, yakni tentang penyelesaian masalah bersama teman dan kebebasan membuat jadwal kerja.

Hal penting yang perlu dicermati oleh PT. XYZ terkait kepuasan kerja ini adalah faktorfaktor yang berpengaruh pada terhadap kepuasan kerja karyawan. Setiap karyawan memiliki standar kepuasan tersendiri, dan tiap perusahaan juga memiliki ukuran tersendiri. Selain masalah gaji, PT. XYZ perlu melakukan observasi atau Focus Group Discussion (FGD) dengan karyawan terkait unsur-unsur penentu kepuasan kerja mereka. Perusahaan dapat menggunakan media atau expert dari luar perusahaan untuk mengggali unsur-unsur ini. Misalnya dengan mengadakan pelatihan, gathering, atau sharing session antar karyawan dan pimpinan. Cara-cara seperti ini biasanya lebih tepat dan tidak terlalu formil, namun sangat bermanfaat dalam meningkatkan hubungan baik antara pimpinan dan karyawan, serta membentuk komunikasi terbuka di perusahaan.

\section{SARAN}

\section{Saran Teoretis}

Berdasarkan hasil analisis data penelitian, 51,5\% variansi kinerja karyawan dipengaruhi oleh faktor lain di luar variabel penelitian ini. Hal ini menunjukkan bahwa masih banyak faktor lain yang dapat berpengaruh terhadap kinerja karyawan, sehingga dapat diteliti di penelittian selanjutnya, seperti gaya kepemimpinan, motivasi kerja, kompensasi, budaya organisasi dan stres kerja. Penelitian selanjutnya juga dapat mengembangkan teknik analisis dengan menggunakan analisis Structural Equation Modelling (SEM), sehingga hasil analisis dapat lebih menggambarkan pengaruhnya.

\section{Saran Praktis}

1) Keterikatan kerja terbukti mempunyai peran terhadap kinerja karyawan. Dengan demikian, agar kinerja karyawan terus meningkat sebaiknya perusahaan dapat terus memperhatikan rasa keterikatan kerja dari karyawan. Perusahaan harus mempertahankan keterikatan kerja karyawan tersebut dengan cara menggali faktor-faktor pendukung meningkatnya keterikatan kerja karyawan. 
2) Iklim organisasi yang terbukti berpengaruh terhadap kinerja karyawan, sehingga diharapkan PT. XYZ dapat mengembangkan iklim organisasi dengan lebih baik lagi agar dapat membantu kinerja karyawan. Dengan cara memasukkan pengembangan iklim organisasi dalam rencana strategis PT. XYZ.

3) Kepuasan kerja yang didalam penelitian ini berpengaruh juga terhadap kinerja dari karyawan. Kepuasan kerja juga dapat ditingkatkan sehingga dapat memotivasi lebih baik lagi yang berguna untuk membantu menaikkan kinerja karyawan.

\section{DAFTAR PUSTAKA}

Ardana, I. K., Mujiati, N. W., \& Utama, I. W. M. (2012). Manajemen sumber daya manusia. Yogyakarta: Graha Ilmu.

Khandekar, A., \& Sharma, A. (2006). Organizational learning and performance: Understanding Indian scenario in present global context. Education+ Training, 48(8/9), 682-692.

Koesmono, H. T. (2005). Pengaruh Budaya Organisasi Terhadap Motivasi Dan Kepuasan Kerja Serta Kinerja Karyawan Pada Sub Sektor Industri Pengolahan Kayu Skala Menengah Di Jawa Timur. Jurnal Manajemen Dan Kewirausahaan, 7(2), 171-188.

Koopmans, et al. (2014). Improving the individual work performance questionnaire using rasch analysis. J Appl Meas, 15(2), 160-175.

Schaufeli, W. B. (2012), -About the Dark and Bright Sides of Self-efficacy: Workaholism and Work Engagement, The Spanish Journal of Psychology, 15, 688- 701.

Smith, A. et al, 2000. The Scala of Occupational Stress : The Bristol Stress and Health at Work Study. Health and Safety Axecutive. U.K

Wirawan, 2007. Budaya dan Iklim Organisasi. Jakarta : Salemba Empat 